\title{
LUMINOUS PROPERTIES OF ELECTRICALLY CONDUCT- ING HELIUM GAS. II. REPRODUCIBILITY
}

\author{
By P. G. Nutting
}

Since the publication of a preliminary report ${ }^{1}$ under the above title, a set of about 50 helium tubes has been tested at the Bureau of Standards, the tubes being intercompared both as regards total light and line by line. The results of this reproducibility test are of interest in connection with the possible use of the helium tube as a primary photometric standard as well as of general interest. These tubes were prepared and operated in accordance with specifications shown by preliminary study to be most suitable; except for slight unavoidable differences, all were alike and were operated alike.

Preliminary work on the variation of light emitted by helium tubes with the current through the tube, the potential gradient in the capillary, gas density, frequency of alternation of current, and diameter of bore of capillary was done in $1906-7$ and described in this bulletin (loc. cit.). This investigation showed that the most suitable bore was $2 \mathrm{~mm}$ and the best current 25 milliamperes. Under these conditions the ratio of light to current is very nearly constant, and the light emitted is quite independent of gas density over a range of pressure from 4 to $7 \mathrm{~mm}$, falling off rapidly at pressures both below 3 and above $8 \mathrm{~mm}$. This independence of gas density is of vital importance, since this gas density is the only uncontrollable variable in the finished tube and for the 
practical reason that gas densities are not easily measured with precision during filling. The light emitted was further shown to be the same whether the tube was operated on direct current or on alternating current of 60 or of 900 cycles.

This preliminary work also showed that there was great room for improvement in the wall of the capillary portion of the tubes. Variations in thickness produced such an unequal distribution of light that results even with rotating tubes were uncertain from this cause. Accordingly, capillary tubing in $10 \mathrm{~cm}$ lengths was ordered from Baudin, of Paris, for the new set of tubes.

This new tubing was very uniform in bore (I.99-2.07 $\mathrm{mm}$ ) and in wall thickness, and fairly free from striations. The mean bore of the middle $7 \mathrm{~cm}$ was determined with a mercury thread. The tubes were made up and filled with pure helium from Tyrer in the spring of I909. The electrodes used were aluminum disks I mm thick and $25 \mathrm{~mm}$ diameter; the bulbs were spherical, $35 \mathrm{~mm}$ in diameter.

The filling was done with a good Geryk pump without subjecting the tubes or gas to contamination by either mercury or rubber tubing. The exhaustion was done with a heavy current passing through the tube and was carried to a nonconducting stage in about 15 minutes. No attempt was made to eliminate all the hydrogen in the electrodes, but so little was left that what appeared (if any) on standing six months disappeared in a few seconds on starting the tubes. No attempt was made to adjust the helium pressure to exactly $5 \mathrm{~mm}$, but care was taken not to deviate more than I mm from this standard.

In July, I909, two months after filling, each tube was run a few minutes at $25 \mathrm{~m}$.a. for inspection in preparation for the photometric test. About half of the tubes showed hydrogen, which disappeared in 2 to ro seconds.

In September, I9I0, the tubes, having lain idle for I 4 months, were intercompared line by line with a spectrophotometer, necessitating a run of about I5 minutes per tube. Each pair of tubes was operated on the same circuit in series. The yellow lines, 587 , were set at equality, then the relative intensities of four other lines (red 668, green 50I, blue 47 r, and violet 447) were determined. These observations and their reduction were made by Dr. Orin Tugman, then of this Bureau. 
The results of chief interest in this mass of data are the average deviations from the mean, given below for 46 tubes:

\begin{tabular}{|c|c|c|c|c|c|}
\hline & 668 & $5^{87}$ & $5 \mathrm{OI}$ & $47 \mathrm{I}$ & \\
\hline Cإ & Red & Yellow & Green & Blue & Violet \\
\hline dverage deviation & 0.016 & 0.00 & 0.016 & 0.018 & 0.015 \\
\hline
\end{tabular}

With tubes exactly alike, the maximum deviations to be expected would be twice the difference limen or about 0.04 , the limen entering once in setting the yellow comparison lines to equality and a second time in setting on the pair to be observed. The average deviations to be expected are half this, or 0.02 , since readings differing from the actual value by less than the limen are equally probable. The observed average deviations are for every line less than those to be expected if the observations had been on tubes identical in every respect; hence we may conclude that these 46 tubes show spectral reproducibility; that is, they are all of the same color to within differences much too small to determine by visual methods.

Variations of line intensity with current were studied over a wide range of current (o-450 $\mathrm{m}$.a. in a $3 \mathrm{~mm}$ capillary) by the writer in collaboration with Dr. Tugman, using specially constructed tubes. $^{2}$ All the eight prominent lines studied showed a variation with current having the same characteristic form as the curve of total light as a function of current published in the first paper (loc. cit.). The five lines 47 I, 492, 504, 587, and 668 showed nearly the same variation with current, 447 and 501 a more rapid and 706 a less rapid variation than these. A wide variation in current will therefore produce a slight variation in the color of a helium tube, but the change in a small range at low current densities, say from 20 to $30 \mathrm{~m}$.a., would not be measurable.

Seven of the eight lines studied (loc. cit.) showed but slight relative variations with gas density over a range from 2 to Io $\mathrm{mm}$, but the faint green line 504 is relatively much brighter at low pressures. This accounts for the relatively greenish hue exhibited in tubes containing helium at very low pressures.

A full photometric test of 38 tubes was made in May, I9I I, in the photometric section of this Bureau. There were four observers $\mathrm{M}, \mathrm{A}, \mathrm{J}$, and $\mathrm{N}$, all experienced in photometry. The tubes were rotated at a speed of about $\mathrm{I} .2$ revolutions per second during 
observation. The current used was $0.025 \pm 0.0001$ ampere, from a 5000-volt 6o-cycle transformer, using current from a special generator run by a battery.

The results are given in the following table:

\begin{tabular}{|c|c|c|c|c|c|c|c|c|}
\hline $\begin{array}{c}\text { I, Tube } \\
\text { num- } \\
\text { ber }\end{array}$ & $\begin{array}{c}\text { II, Hy- } \\
\text { drogen } \\
\text { (sec) }\end{array}$ & $\underset{\text { (mm) }}{\text { III, Bore }}$ & IV, Length & $\mathrm{V}, \underset{37 \mathrm{~cm}}{\mathrm{~cm}}$ at & $\begin{array}{l}\text { VI, Mean } \\
\text { deviation } \\
\text { reading }\end{array}$ & VII, $\mathrm{cp} / \mathrm{cm}$ & $\begin{array}{l}\text { VIII, } \mathrm{cp} / \mathrm{cm} \\
2 \mathrm{~mm} \text { bore }\end{array}$ & $\begin{array}{l}\text { IX, Tube } \\
\text { deviation }\end{array}$ \\
\hline 1 & 4 & 2. 062 & 5.038 & 1. 555 & 0.033 & 0.3088 & 0.3119 & -0.0028 \\
\hline 2 & 2 & 50 & 4. 996 & 560 & 15 & 3122 & 3147 & $-\quad 00$ \\
\hline 3 & 5 & 24 & 5. 166 & 632 & 13 & 3159 & 3171 & + \\
\hline 5 & 0 & 10 & 5.056 & 592 & 15 & 3148 & 3153 & + \\
\hline 6 & 10 & 70 & 5.129 & 585 & 03 & 3090 & 3125 & $-\quad 22$ \\
\hline 10 & 4 & 2. 064 & 5.135 & 1. 582 & 0.009 & 0.3082 & 0.3114 & -0.0033 \\
\hline 11 & 0 & 44 & 5.120 & 580 & 20 & 3086 & 3108 & $\begin{array}{l}-\quad 39 \\
\end{array}$ \\
\hline 12 & 2 & 22 & 4. 976 & 562 & 12 & 3139 & 3150 & + \\
\hline 15 & 0 & 50 & 5. 059 & 589 & 15 & 3141 & 3166 & $+\quad 19$ \\
\hline 16 & 5 & 00 & 5.121 & 612 & 15 & 3148 & 3148 & +1 \\
\hline 17 & 0 & 2.052 & 5.157 & 1.630 & 0.015 & 0.3161 & 0.3187 & +0.0040 \\
\hline 18 & 2 & 32 & 5.067 & 566 & 15 & 3089 & 3105 & $-\quad 42$ \\
\hline 19 & 0 & 60 & 5.114 & 546 & 8 & 3025 & 3055 & 92 \\
\hline 20 & 3 & 46 & 5. 103 & 574 & 17 & 3084 & 3107 & - \\
\hline 21 & 4 & 40 & 5.068 & 602 & 18 & 3161 & 3181 & $+\quad 34$ \\
\hline 23 & 0 & 2. 024 & 5.075 & 1.552 & 0.019 & 0.3058 & 0.3070 & -0.0077 \\
\hline 24 & 2 & 32 & 5.065 & 594 & 17 & 3148 & 3164 & $+\quad 17$ \\
\hline 25 & 2 & 26 & 4. 970 & 570 & 28 & 3160 & 3173 & + \\
\hline 27 & 6 & 14 & 5.139 & 642 & 15 & 3196 & 3203 & + \\
\hline 28 & 2 & 64 & 5. 121 & 605 & 07 & 3135 & 3167 & + \\
\hline 29 & 0 & 2.000 & 5.093 & 1.604 & 0.016 & 0.3151 & 0.3151 & +0.0004 \\
\hline 31 & 3 & 70 & 5.037 & 593 & 16 & 3164 & 3199 & $+\quad 52$ \\
\hline 32 & 8 & 66 & 5. 167 & 604 & 28 & 3105 & 3138 & - \\
\hline 33 & 5 & 60 & 5. 016 & 558 & 11 & 3107 & 3137 & 10 \\
\hline 34 & 0 & 08 & 5.100 & 591 & 13 & 3120 & 3124 & $-\quad 23$ \\
\hline 35 & 3 & 2.022 & 4. 997 & 1.577 & 0.024 & 0.3156 & 0.3167 & +0.0020 \\
\hline 36 & 0 & 42 & 5.016 & 601 & 21 & 3192 & 3213 & +66 \\
\hline 38 & 0 & 38 & 5. 138 & 561 & 35 & 3037 & 3056 & - \\
\hline 39 & 5 & 00 & 5.115 & 621 & 22 & 3169 & 3169 & + \\
\hline 41 & 0 & 54 & 4.855 & 542 & 16 & 3177 & 3204 & $+\quad 57$ \\
\hline 42 & 2 & 2. 054 & 4. 916 & 1.545 & 0.009 & 0.3145 & 0.3172 & +0.0025 \\
\hline 43 & 5 & 80 & 5.043 & 565 & 12 & 3103 & 3143 & -6 \\
\hline 45 & 0 & 04 & 5. 152 & 646 & 13 & 3196 & 3198 & + \\
\hline 46 & 0 & 1.992 & 5.113 & 596 & 05 & 3125 & 3121 & - \\
\hline 47 & 5 & 2. 034 & 5.003 & 519 & 15 & 3035 & 3052 & - \\
\hline 49 & 5 & 2.090 & 5. 134 & 1.592 & 0.013 & 0.3101 & 0.3146 & -0.0001 \\
\hline 54 & 2 & 62 & 4. 998 & 558 & 07 & 3150 & 3181 & $+\quad 34$ \\
\hline 55 & 0 & 54 & 5. 117 & 618 & 18 & 3162 & 3189 & $+\quad 42$ \\
\hline Means & & & & & 0.015 & & $\begin{array}{r}0.3147 \\
\pm 0.0005\end{array}$ & $\begin{array}{r}0.0033 \\
=1.15 \%\end{array}$ \\
\hline
\end{tabular}


I. Tube numbers.

II. The time of disappearance of the hydrogen showing (if at all) after the current was started, the full $25 \mathrm{~m}$.a. being turned on in each case. The tubes had not been operated for eight months and over half of them showed some hydrogen on first starting. There appears to be no relation between the presence of this transient hydrogen and the subsequent light emission.

III. The mean bore of the capillary as determined with a mercury thread before the tubes were made up.

IV. The length of capillary between the screening clips at the ends.

V. The luminous flux at about $37 \mathrm{~cm}$ from the tube center approximately in international candles. These values are the means for the four observers, each observer taking from io to 20 readings by an automatic recording device. The individual variations from the mean are not reproduced here but are summarized below. Each tube read high at the start but reached a steady value after running less than two minutes.

VI. The average deviation from the mean reading (Column V) due to the observers; that is, the average of the four separate deviations of the four observers. This shows how the mean reading of each observer differs, on the average, from the mean of all.

VII. The luminous flux (V) divided by the length of capillary (IV) radiating. The anti tangent correction, applicable on account of the source being linear, was not applied, as it is very small and very nearly the same for all tubes.

VIII. The same quantity as VII, but corrected for the slight differences in bore. In the earlier paper (1908, loc. cit., p. 52I) it was shown that the bore correction for bores near $2 \mathrm{~mm}$ is very nearly linear and is $-0.0050 \mathrm{cp}$ for $+0.10 \mathrm{~mm}$ difference in bore. This correction is here applied to reduce all tubes to the equivalent of $2 \mathrm{~mm}$ bore. The mean value of all the tubes is $0.3147 \pm 0.0005$ candles per $\mathrm{cm}$ length of capillary per $2 \mathrm{~mm}$ bore, the uncertainty indicated being the computed probable error.

IX. The deviation of each tube from the mean of all the tubes; this is the measure of reproducibility. The average deviation is 0.0033 , or about I.I 5 per cent, the maximum deviation (Nos: 19, $23,38,45,47)$ less than 3 per cent. These larger deviations show 
no definite relation to deviations in readings, amount of initial hydrogen in the tubes, nor to abnormal gas density or bore of capillary. Tubes $20,2 \mathrm{I}$, and 47 showed pressures as low (estimated by width of dark space) as $3 \mathrm{~mm}$, Io and 27 as high as $7 \mathrm{~mm}$, all others being apparently between 4 and $6 \mathrm{~mm}$.

Readings on $15,27,32$, and 33 were repeated after 2 days as a photometric test.

\begin{tabular}{|c|c|c|c|c|}
\hline Tube & $\mathrm{cp} / \mathrm{cm}$ first & $\mathrm{cp} / \mathrm{cm}$ second & Diff. & $\begin{array}{l}\text { Mean deviation } \\
(\mathrm{cp} / \mathrm{cm})\end{array}$ \\
\hline 15 & 0.3146 & 0.3196 & +0.0050 & 0.0026 \\
\hline 27 & 0.3182 & 0.3177 & -0.0005 & \\
\hline 32 & 0.3116 & 0.3152 & +0.0036 & \\
\hline 33 & 0.3117 & 0.3132 & +0.0015 & \\
\hline
\end{tabular}

Readings, on 27 and 45 were taken at 20.225 .0 and 29.9 m. a. current.

\begin{tabular}{c|c|c|c}
\hline Current & 20.2 & 25.0 & 29.9 m. a. \\
\hline 27 & 1.320 & 1.651 & 1.945 \\
45 & 1.331 & 1.646 & 1.962 \\
\hline
\end{tabular}

Life tests were made on a number of the tubes at 25 m.a. All finally developed hydrogen, the amount of hydrogen increasing about in proportion to the amount of metal deposit on the wall of the bulb. None of the seven tubes showed any definite increase or decrease in light emission up to the time the hydrogen began to show distinctly. This occurred after 5 to 5 hours in different tubes. Tubes would probably show a longer life if constructed with larger bulbs, say $50 \mathrm{~mm}$ in diameter instead of $35 \mathrm{~mm}$.

An analysis of the readings of the individual observers shows that they read on an average as follows:

$\begin{array}{lcccc}\text { Observer...... } & \text { M } & \text { A } & \text { J } & N \\ \text { Average reading } & 0.019 \text { low } & 0.002 \text { high } & 0.024 \text { high } & 0.009 \text { low }\end{array}$ showing the tendency to estimate the intensity differently. For example, $J$ read high throughout, his reading being in every case higher than the average for the four observers. Taking the devia- 
tion of each observer's reading from the mean reading of the four observers and finding the average deviation of these deviations from their mean value we have:

$\begin{array}{lcccc}\text { Observer } \ldots \ldots \ldots \ldots \ldots \ldots & \text { M } & \text { A } & \text { J } & \text { N } \\ \text { Deviation of deviation..... } & \text { 0.010 } & 0.006 & 0.010 & 0.008\end{array}$

This is an indication of each observer's consistency in reading, a measure of his tendency to form a criterion of equality and hold to it throughout the series.

Finally the mean deviation for all observers on all tubes was 0.015 or 0.0030 candles per $\mathrm{cm}$. Eliminating this error of observation from the mean tube deviation (0.0033) leaves $\left((0.0033)^{2}-\right.$ $\left.(0.0030)^{2}\right)^{1 / 2}=0.0014 \mathrm{cp} / \mathrm{cm}=0.4$ per cent for the residual uncertainty in the final value of the $\mathrm{cp} / \mathrm{cm}$ due to accidental variations in the tubes.

\section{SUMMARY}

A number of helium tubes were constructed, having glass capillaries very approximately of $2 \mathrm{~mm}$ bore and $7 \mathrm{~cm}$ long, with spherical end bulbs of $3.5 \mathrm{~cm}$ diameter, provided with aluminum electrodes $2.5 \mathrm{~cm}$ in diameter. The candlepower per centimeter length of tube (of the middle $5 \mathrm{~cm}$ of the capillary tube), when a current of 25 milliamperes was passing through the tube, was found to be 0.3I5 international candles. The effect of small variations in the frequency and strength of current, in the diameter of the capillary, in the pressure of the helium gas, etc., and the life of the tubes, are discussed.

The mean deviation in candlepower per cm length of tube from the mean of all the 38 tubes was I.I 5 per cent. The maximum deviation of any one tube was 3 per cent.

The four observers read slightly differently, due probably to different color sensibilities. M read I.2 per cent low, A O.I per cent high, $\mathrm{J}$ I.5 per cent high, and $\mathrm{N} 0.5$ per cent low on an average, compared with their mean.

Each individual observer varied somewhat in his criterion of equality. The deviations in the deviations from the mean readings amounting to, on an average, in the case of $\mathrm{M} 0.6$ per cent, A 0.4 per cent, $\mathrm{J} 0.6$ per cent, and $\mathrm{N} 0.5$ per cent. 
The chief improvement to be made in the next set of tubes is in using capillary tubing freer from striations. These long drawn out bubbles are in effect cylindrical lenses and with a rotating tube the sharp flicker produced by them is more troublesome in taking readings than the color difference. To secure a longer life either the bulbs will be made larger $(40 \mathrm{~mm}$ ) or the electrodes smaller $(20 \mathrm{~mm})$ in diameter.

Washington, August 25, I9II. 